\title{
Tratamento cirúrgico dos aneurismas e dissecções do arco aórtico
}

\author{
Bayard GONTIJO FILHO*, Fernando Antônio FANTINI*, Flávio COLLUCI*, Mario O. VRANDECIC*
}

RBCCV 44205-469

\begin{abstract}
Gontijo Filho B, Fantini F A, Colluci F, Vrandecic M O - Tratamento cirúrgico dos aneurismas e dissecções do arco aórtico. Rev Bras Cir Cardiovasc 1999; 14 (4): 285-9.

RESUMO: No período de jan/1990 a mar/1999, foram realizados 354 operações para tratamento de lesões da aorta torácica em nosso Serviço. Destas, 47 foram relacionadas a procedimentos no arco aórtico; $31(66,0 \%)$ pacientes eram do sexo masculino e a idade variou de 26 a 74 anos ( $m=54,9 \pm 10,9)$. A dissecção aórtica foi responsável pela indicação cirúrgica em 33 (70,2\%) pacientes e os aneurismas fusiformes ou saculares em 14 (29,8\%). A operação foi indicada em caráter de urgência em 10 (21,3\%) pacientes, havendo 4 casos com sinais de rotura; $11(23,4 \%)$ pacientes já haviam sido submetidos a operação cardíaca prévia. $\mathrm{O}$ acesso cirúrgico foi a esternotomia mediana (42 casos) ou a toracotomia esquerda ou bilateral (5 casos). Hipotermia profunda com parada circulatória (PC) foi empregada em $97,8 \%$ dos casos com o tempo PC variando de 15 a 60 minutos $(m=30,6 \pm 12,6)$. A técnica do tipo hemiarco anterior foi empregada em $19(40,4 \%)$ pacientes, o hemiarco posterior em 5 (10,6\%), a substituição total em 18 (38,3\%), plastia em 4 (8,5\%) e derivação extra-anatômica em $1(2,1 \%)$. Foram realizados os seguintes procedimentos concomitantes: substituição da aorta ascendente por conduto valvulado (15), revascularização miocárdica (9), tromba de elefante (5) e troca valvar aórtica (3). A mortalidade hospitalar foi de 12,3\% (6 pacientes) sendo a complicação não fatal mais freqüente a insuficiência respiratória (7 casos). A análise dos fatores determinantes de mortalidade hospitalar demonstraram tendência estatística para idade acima de 60 anos $(p=0,17)$ e para portadores de dissecção aguda $(p=0,07)$. Dos 41 pacientes que receberam alta, 39 foram seguidos por um período de 1 mês a 9 anos. Houve 3 óbitos, sendo 1 por AVC e 2 em reoperações, necessárias em 5 pacientes. A sobrevida de 9 anos é de $80,85 \%$.
\end{abstract}

DESCRITORES: Aneurisma de aorta torácica, cirurgia. Aneurisma dissecante, cirurgia. Aorta torácica, cirurgia.

\section{INTRODUÇÃO}

Procedimentos cirúrgicos ao nível do arco aórtico sempre ofereceram grandes dificuldades ao cirurgião cardiovascular e quase sempre foram acompanhados de altos índices de morbi-mortalidade. Desde o primeiro relato de DeBAKEY et al. (1), em 1957, da primeira ressecção do arco aórtico com sucesso, muito progresso foi alcançado, principalmente a partir de 1975, quando GRIEP et al. (2) definitivamente introduziram a hipotermia profunda com parada circulatória na abordagem cirúrgica destas lesões.
Importantes relatos foram demonstrando a crescente segurança operatória com resultados progressivamente melhores, como os publicados por SVENSSON et al. (3) e COSELLI et al. (4). Apesar disto, ainda persistem indagações particularmente quanto a melhor tática cirúrgica e os melhores métodos de proteção cerebral durante a operação. Apresentamos de forma retrospectiva os nossos resultados em um grupo de 47 pacientes operados consecutivamente, para correção de aneurismas ou dissecções do arco aórtico.

Trabalho realizado no Biocor Instituto. Belo Horizonte, MG, Brasil.

Apresentado ao 26ํㅡㄹ Congresso Nacional de Cirurgia Cardíaca. Fortaleza, CE, 8 a 10 de abril, 1999.

* Do Biocor Instituto.

Endereço para correspondência: Bayard Gontijo Filho. Caixa Postal 106. Belo Horizonte, MG, Brasil. CEP: 30580-130. Tel. (031) $286-2257$.

e-mail: biocor@biocor.com.br 


\section{CASUÍSTICA}

No período de jan/90 a mar/99 foram realizados 354 procedimentos para correção de doenças da aorta torácica no Biocor Instituto, sendo que em 47 $(13,3 \%)$ ocasiões foi abordada a região do arco aórtico (13,3\%). Dos 47 pacientes, $31(66,0 \%)$ eram do sexo masculino e $16(34,0 \%)$ do sexo feminino. A idade variou de 26 a 74 anos $(m=54,9 \pm 10,9)$. A dissecção da aorta foi responsável pela indicação cirúrgica em 33 pacientes, sendo a dissecção aguda em $9(19,1 \%)$ pacientes e a dissecção crônica em $24(51,1 \%)$. Os demais pacientes apresentavam aneurismas fusiformes (10/21,3\%) ou saculares (4/ $8,6 \%)$. A principal queixa clínica foi a dor torácica $(72,9 \%)$ e a insuficiência cardíaca congestiva geralmente secundária a insuficiência aórtica $(17,0 \%)$. O crescimento do aneurisma gerou sintomas com sinais compressivos em 4 pacientes, sendo em 3 ao nível da traquéia e brônquio principal esquerdo e em outro ao nível da artéria pulmonar direita; 38 (80,8\%) pacientes apresentavam hipertensão arterial associada e $9(19,14 \%)$ tinham evidência de doença coronária significativa. A operação foi indicada em caráter de urgência em $10(21,3 \%)$ pacientes, havendo sinais de rotura aórtica em 4 deles; 11 $(23,40 \%)$ pacientes haviam sido submetidos a um ou mais procedimentos intracardíacos (Tabela 1).

\section{Técnica Cirúrgica}

Apenas 1 paciente com quadro clínico de AVC no pré-operatório a trombose extensa dos vasos cervicais foi operado sem a utilização de circulação extracorpórea no início da experiência, sendo realizado desvio extra-anatômico e revascularização individual dos vasos supra aórticos. Neste caso, através de uma incisão anterior, foi feito by-pass da aorta ascendente para a aorta abdominal com prótese de Dacron e revascularização sucessiva com próteses retas do tronco braquiocefálico, carótida esquerda e subclávia esquerda promovendo exclusão do arco aórtico e perfusão retrógrada da aorta torácica.

Nos demais casos empregamos circulação extracorpórea e hipotermia profunda com oxigenador

TABELA 1

CIRURGIA DO ARCO AÓRTICO

PACIENTES COM CIRURGIA CARDÍACA PRÉVIA

\begin{tabular}{lc}
\hline * Dissecção aguda (plastia) & 3 \\
* Dissecção aguda (tubo não valvulado) & 3 \\
${ }^{*}$ Revascularização miocárdica & 2 \\
${ }^{*}$ Troca de valva aórtica & 2 \\
* Aneurisma de aorta ascendente & 1 \\
TOTAL & $11(23,4 \%)$ \\
\hline
\end{tabular}

de membranas e com hemodiluição. O acesso foi a esternotomia mediana em 42 vezes e a toracotomia esquerda ou bilateral em 5 vezes. A perfusão foi realizada através da artéria femoral e canulação do átrio direito com cânula única na maioria dos pacientes. Em 2 pacientes com evidências tomográficas de íntimo contacto da aorta com o esterno realizamos canulação fêmoro-femoral e entramos em perfusão antes da esternotomia. A hipotermia profunda foi induzida até $16^{\circ} \mathrm{C}$ com controle da temperatura de orofaringe e retal, sendo empregada a técnica de "alpha-stat" para manipulação do equilíbrio ácidobásico. Em 12 pacientes com períodos de parada circulatória acima de 40 minutos foi empregada a perfusão arterial retrógrada (PCR) pela veia cava superior com fluxo de aproximadamente $350-500$ $\mathrm{ml} / \mathrm{min}$. O tempo de parada circulatória variou de 15 a $60 \min (m=30,6 \pm 12,6)$.

Dos 47 pacientes, $11(23,4 \%)$ já haviam sido submetidos a uma operação cardíaca, seja envolvendo a aorta ascendente ou outro tipo de procedimento: 6 haviam sido operados para tratamento de dissecção aguda da aorta, 2 a revascularização miocárdica, 2 a troca de valva aórtica e 1 a correção de aneurisma da aorta ascendente. Quanto ao tipo de procedimento efetuado (Tabela 2), 19 (40,4\%) pacientes com acometimento basicamente da aorta ascendente e início do arco aórtico foram submetidos a correção do tipo hemiarco anterior com uma anastomose bizelada compreendendo toda a base do arco aórtico. Neste grupo vários pacientes com dissecção aórtica necessitaram ressecção e fixação das lâminas dissecadas concomitantemente à reconstrução do arco. Nos $5(10,6 \%)$ casos de acometimento do arco aórtico posterior e da aorta descendente realizamos correção semelhante à anterior, porém ao nível do joelho aórtico posterior (hemi-arco posterior) através de toracotomia bilateral. Nos casos de aneurismas fusiformes ou com acometimento e dilatação de todo arco pela dissecção aórtica, foi realizada reconstrução total do arco através de anastomose látero-lateral da prótese a uma ilha de tecido aórtico contendo os vasos supraaórticos (18/38,3\%). Quando havia dilatação aneu-

TABELA 2

\begin{tabular}{lrc}
\hline \multicolumn{3}{c}{ CIRURGIA DO ARCO AÓRTICO } \\
\hline TÉCNICAS DE & MORTALIDADE \\
RECONSTRUÇÃO & & \\
\hline - Hemiarco anterior & 19 & 1 \\
- Hemiarco posterior & 5 & 1 \\
- Substituição total & 18 & 4 \\
- Plastia (saculares) & 4 & - \\
- Derivação extra-anatômica & 1 & - \\
\hline TOTAL & 47 & 6 \\
\hline
\end{tabular}


rismática de algum ramo supra aórtico este era reconstruído individualmente. Os aneurismas saculares, em número de 4 (8,5\%), foram corrigidos com plastia de pericárdio bovino associada a revascularização dos troncos supra-aórticos, quando necessário.

Foram necessários vários procedimentos concomitantes (Tabela 3); 18 pacientes necessitaram correção de lesão valvar aórtica através de condutos valvulados (15) ou de troca valvar aórtica (3), 9 pacientes foram submetidos a revascularização miocárdica e em 5 pacientes foi acrescentada tromba de elefante na aorta descendente, segundo técnica preconizada por BORST et al. (5).

\section{RESULTADOS}

A mortalidade hospitalar foi de $6(12,8 \%)$ pacientes. As causas de óbito foram a síndrome de baixo débito por insuficiência ventricular esquerda (3); insuficiência respiratória e renal (1), hemorragia (1) e arritmia ventricular (1). Dos 6 óbitos, 3 ocorreram em pacientes portadores de dissecção aguda, 2 em pacientes com aneurismas fusiformes e 1 portador de dissecção crônica. A análise estatística individual dos fatores determinantes de mortalidade hospitalar demonstraram apenas uma tendência de significância em dois pontos: idade superior a 60 anos $(p=0,17)$ e a presença de dissecção aguda $(p=0,07)$. A complicação mais freqüente no pós-operatório imediato foi a insuficiência respiratória com assistência mecânica prolongada em 7 (14,9\%) pacientes, 2 pacientes foram reoperados para revisão de hemostasia; 2 pacientes apresentaram arritmia ventricular; 1 paciente apresentou mediastinite. Uma paciente evoluiu com paraplegia após a operação do arco posterior associada a substituição de toda a aorta descendente até junto ao tronco celíaco.

Com relação a manifestações neurológicas centrais $(23,4 \%)$, houve 1 caso de AVC definitivo, 2 casos de AVC temporário com recuperação completa e 8 casos de confusão mental temporária. O tempo de parada circulatória superior a 30 minutos correlacionou a maior incidência de confusão mental pós-operatória $(p=0,04)$.

TABELA 3

CIRURGIA DO ARCO AÓRTICO PROCEDIMENTOS CIRÚRGICOS ASSOCIADOS

\begin{tabular}{lc}
\hline * Conduto valvulado & 15 \\
${ }^{*}$ Troca de valva aórtica & 3 \\
* Revascularização miocárdica & 9 \\
${ }^{*}$ Tomba de elefante & 5 \\
TOTAL & $32(68 \%)$ \\
\hline
\end{tabular}

Dos 41 pacientes que receberam alta hospitalar, 39 (95,12\%) foram seguidos por um período que variou de 30 dias a 9 anos. Houve 3 óbitos tardios, sendo um óbito devido a acidente vascular cerebral no $6^{\circ}$ ano de pós-operatório e os outros dois em um grupo de 5 pacientes que necessitaram reoperações tardias; 3 pacientes foram reoperados para completar o $2^{\circ}$ tempo da tromba de elefante com substituição da aorta descendente ou toracoabdominal, com 1 óbito por complicações metabólicas. Outro paciente foi reoperado com rotura de pseudo-aneurisma e fístula aorto-esofágica em quadro de emergência e faleceu durante o segundo procedimento. O outro paciente foi submetido a revascularização miocárdica no $17^{\circ}$ mês de pós-operatório. A sobrevida global a longo prazo é de $80,85 \%$. Existem em controle 2 pacientes com insuficiência moderada da valva aórtica nativa e outro com insuficiência aórtica leve, porém não demonstrando critérios hemodinâmicos para reoperação. A paciente que apresentou paraplegia encontra-se com seqüela $e$ outro paciente tem o diagnóstico de câncer de pulmão, atualmente em tratamento clínico.

\section{COMENTÁRIOS}

Os resultados atuais da correção cirúrgica das doenças do arco áortico demonstram que estas lesões podem hoje ser abordadas com maior segurança, não constituindo o mesmo desafio de anos atrás. CRAWFORD et al. (6) relatam uma mortalidade hospitalar de $25 \%$ até 1980 e uma redução significativa para $11 \%$ até 1988 , devido a introdução e aperfeiçoamento de técnicas e materiais. Outros relatos atuais situam a mortalidade hospitalar entre $6 \%$ e $19 \%(4,7)$ com os nossos resultados de $12,8 \%$ dentro dos parâmetros mundiais. Vários fatores concorreram para este progresso, sendo que, a nossa ver, a introdução definitiva da hipotermia profunda por CRIEP et al. (8) em 1975 foi, seguramente, o fator isolado mais importante. A parada circulatória permite um campo cirúrgico excelente sem sangue, além de eliminar a necessidade de dissecção dos vasos supra-aórticos. O tempo de parada circulatória e os diversos métodos para proteção cerebral constituem os principais pontos de discussão.

Vários relatos comprovam a relação direta entre o tempo de parada circulatória (PC) e morbimortalidade. SVENSSON et al. (3), em uma serie de 656 pacientes, demonstraram que períodos de PC acima de 45 min aumentam as complicações neurológicas, enquanto que períodos superiores a $60 \mathrm{~min}$ aumentam a mortalidade pós-operatória. Por outro lado, existe consenso de que períodos inferiores a 30 minutos em temperatura corporal de $18^{\circ} \mathrm{C}$ são bastante seguros, com possibilidade remota de 
complicação neurológica (8-10). Entretanto, em algumas circunstâncias torna-se necessário um prolongamento do período de isquemia cerebral além de 30-40 min. Vários métodos têm sido preconizados para prolongar seguramente o período de $\mathrm{P} C$. A perfusão cerebral anterógrada (PCA) pelas artérias supra-aórticas foi o principal método utilizado antes da introdução clínica de hipotermia profunda em 1975 e ainda hoje tem alguns adeptos. Apesar de aparentes vantagens fisiológicas, vários fatores adversos com a P C A podem ser enumerados: complexidade do sistema de perfusão necessitando, por vezes, várias cânulas para os vasos cerebrais, risco de hipoperfusão cerebral por variações anatômicas e maior risco de embolia cerebral pela manipulação de tecido arterial doente. Desta forma, a PCA não tem sido muito utilizada nos maiores centros mundiais. A perfusão cerebral retrógrada (PCR) através da veia cava superior é hoje talvez o método mais empregado como sistema de proteção cerebral. Seu desenvolvimento teve como base a utilização clínica de PCR em casos de tromboembolismo gasoso maciço per-operatório.

Os trabalhos de UEDA et al. (11) foram os que despertaram o interesse por este método nas operações de arco aórtico. Hoje somam-se vários relatos, justificando o uso de PCR nas operações com parada circulatória (12). Esta técnica, além de perfundir o cérebro eliminando a anóxia isquêmica, teria também a vantagem de diminuir a incidência de AVC por tromboembolismo, pela limpeza retrógrada de micropartículas arteriais. GRIEP et al. (8) chamam atenção para a falta de evidências experimentais convincentes de que a PCR exerça real fator de proteção cerebral a não ser pela manutenção da hipotermia e que seu emprego em normotermia não é aconselhável. USUI et al. (13), em trabalho cooperativo entre vários centros japoneses, encontraram aumento importante de AVC após 60 min de parada circulatória associada a PCR, o que demonstra não ser este ainda um método ideal para longos períodos de parada circulatória. Além disto, quando a pressão da PCR ultrapassou $35 \mathrm{mmHg}$, o risco de disfunção cerebral aumentou significativamente. Nossa estratégia tem sido a de promover uma hipotermia segura através de técnica rigorosa nos concentrando em diminuir ao máximo o tempo de parada circulatória $(8,14)$. A média de 30,6 min de parada circulatória nos nossos pacientes com um tempo máximo de 60 minutos atesta esta preocupação, ao mesmo tempo que demonstra sua eficácia pelo baixo índice de complicações definitivas neurológicas pós-operatórias. A maior incidência de estado confusional pós-operatório, apesar de não trazer grande preocupação, demonstra que a proteção cerebral ainda é um ponto a ser melhor pesquisado. Empregamos a PCR em pacientes com períodos de $\mathrm{P} C$ superiores a $40 \mathrm{~min}$, porém o número pequeno de pacientes e de complicações não permitiu conclusões estatísticas quanto à sua eficácia.

A indução de hipotermia em nossa experiência foi feita lentamente (tempo médio de esfriamento = 32 min), com controle simultâneo de temperatura retal e nasofaríngea, não devendo haver grande diferença $\left(>3^{\circ} \mathrm{C}\right)$ entre as duas. Apesar de alguns autores preconizarem temperaturas entre $20^{\circ}-24^{\circ} \mathrm{C}$ para reparos mais curtos (<20 minutos), utilizamos temperaturas em torno de $16^{\circ}-17^{\circ} \mathrm{C}$ para todas as técnicas com parada circulatória. $\mathrm{O}$ reaquecimento, por seu turno, é mais demorado, com um tempo em torno de 40-45 minutos.

Com relação à abordagem cirúrgica, acreditamos que os aneurismas que acometem o joelho posterior do arco aórtico e a aorta descendente devem ser abordados por toracotomia esquerda ou bilateral. A toracotomia bilateral permite uma boa exposição de toda a aorta torácica até próximo ao diafragma, além de viabilizar outros procedimentos cardíacos concomitantes. ROKKAS \& KOUCHOUKOS (15), em trabalho recente, advogam esta incisão para abordagem conjunta da aorta ascendente, arco e aorta descendente.

A alta incidência de dissecção aórtica em nossa série difere de outros relatos. Acreditamos que este fato se deva à maior freqüência de aneurismas verdadeiros em uma faixa etária mais avançada e, portanto, menos abordada em países com menor expectativa de vida. Nossos resultados confirmam a gravidade das dissecções aórticas agudas com origem no arco aórtico, que foi fator significativo de maior mortalidade hospitalar juntamente com idade superior a 60 anos. Na evolução a longo prazo, foram realizadas 5 reoperações, sendo 4 diretamente relacionadas ao procedimento inicial, o que demonstra a necessidade de um acompanhamento rigoroso após a alta hospitalar.

Em conclusão, os aneurismas e dissecções do arco aórtico podem ser hoje tratados com um índice de morbimortalidade baixo através da hipotermia profunda com parada cardiocirculatória. 
Gontijo Filho B, Fantini F A, Colluci F, Vrandecic M O - Surgical treatment of aneurysms and dissections of the aortic arch. Rev Bras Cir Cardiovasc 1999; 14 (4): 285-9.

ABSTRACT: From Jan/1990 to Mar/1999 we performed 354 operations on the thoracic aorta in our hospital. Among these, 47 procedures involved the aortic arch; 31 patients were male (66.0\%) and ages ranged from 26 74 years (mean $=54.9 \pm 10.9$ ). Aortic dissection was present in 33 patients $(70.2 \%)$ and fusiform or sacular aneurysms in 14 (29.8\%). Previous cardíac procedures had been performed in 11 patients (23.4\%), rupture with cardíac tamponade was present in 4 patients. Median sternotomy was used in 42 cases and bilateral thoracotomy in 5. Deep hypothermia with circulatory arrest was used in $97.8 \%$ of cases with the arrest period ranging from 15 to 60 minutes $(m=30.6 \pm 12.6)$. Anterior hemiarch reconstruction was used in 19 patients $(40.4 \%)$, posterior hemiarch in $5(10.6 \%)$, total arch replacement in 18 (38.3\%) aortoplasty in $4(8.5 \%)$ and extra-anatomic bypass with exclusion in $1(2.1 \%)$. The main associated procedures were: myocardial revascularization (9), ascending aorta replacement by a valved conduit (15), elephant trunk (5) and aortic valve replacement (3). Hospital mortality was $12,3 \%$ (6 patients) and respiratory insufficiency was the most common non-fatal complication (7 cases). Determinant factors for hospital mortality showed a statistical tendency for age over 60 years $(p=0.17)$ and for acute aortic dissection $(p=0.07)$. Late follow-up was achieved in $95.12 \%$ of the hospital survivors. There were 3 late deaths ( 1 cerebro-vascular accident, 2 reoperations). The 9 year survival rate is $80.85 \%$.

DESCRIPTORS: Aortic aneurysm, thoracic, surgery. Aneurysm dissecting, surgery. Aorta, thoracic, surgery.

\section{REFERÊNCIAS BIBLIOGRÁFICAS}

1 DeBakey M E, Cooley D A, Crawford E S, Morris G C $\mathrm{Jr}$ - Successful resection of fusiform aneurysm of aortic arch with replacement by homografts. Surg Gynecol Obstet 1957; 105: 656-64.

2 Griepp R B, Stinson E B, Hollingsworth J F, Buehler D - Prosthetic replacement of the aortic arch. J Thorac Cardiovasc Surg 1975; 70: 1051-63.

3 Svensson L G, Crawford E S, Hess K R et al. - Deep hypothermia with circulatory arrest: determinants of stroke and early mortality in 656 patients. J Thorac Cardiovasc Surg 1993; 106: 19-31.

4 Coselli J S, Buket S, Djukanovie B - Aortic arch operation: current treatment and results. Ann Thorac Surg 1995; 59: 19-27.

5 Borst H G, Walterbusch G, Schaps D - Extensive aortic replacement using "elephant trunk" prosthesis. J Thorac Cardiovasc Surg 1983; 31: 37-40.

6 Crawford E S, Svensson L G, Coselli J S, Safi H J, Hess $\mathrm{R} \mathrm{H}$ - Surgical treatment of aneurysm and / or dissection of the ascending aorta, transverse aortic arch, and ascending aorta and transverse aortic arch: factors influencing survival in 717 patients. $J$ Thorac Cardiovasc Surg 1989; 98: 659-74.

7 Grabenwoger M, Ehrlich M, Cartes-Zumelzu F et al. Surgical treatment of aortic arch aneurysms in profound hypothermia and circulatory arrest. Ann Thorac Surg 1997; 64: 1067-71.

8 Griepp R B, Juvonen T, Griepp E B, McCollough J N, Ergin M A - Is retrograde cerebral perfusion an affective means of neural support during deep hypothermic circulatory arrest? Ann Thorac Surg 1997; 64: 913-6.
9 Ergin M A, Griepp E B, Lansman S L, Galla J D, Levy M, Griepp R B - Hypothermic circulatory arrest and other methods of cerebral protection during operations on the thoracic aorta. J Card Surg 1994; 9: 525-37.

10 Livesay J J, Cooley D A, Reul G J et al. - Resection of aortic arch aneurysms: a comparison of hypothermic techniques in 60 patients. Ann Thorac Surg 1983; 36: 19-28.

11 Ueda Y, Miki S, Kusuhara K, Okita Y, Tahata Y, Yamanaka $\mathrm{K}$ - Surgical treatment of aneurysm or dissection involving the ascending aorta and aortic arch, utilizing circulatory arrest and retrograde cerebral perfusion. J Cardiovasc Surg 1990; 31: 553-8.

12 Okita Y, Takamoto S, Ando M, Morota T, Matsukawa R, Kawashima $Y$ - Mortality and cerebral outcome in patients who underwent aortic arch operations using deep hypothermic circulatory arrest with retrograde cerebral perfusion: no relation of early death, stroke and delirium to the duration of circulatory arrest. $J$ Thorac Cardiovasc Surg 1998; 115: 129-38.

13 Usui A, Abe T, Murase M - Early clinical results of retrograde cerebral perfusion for aortic arch operations in Japan. Ann Thorac Surg 1996; 62: 94-104.

14 Ergin M A, Galla J D, Lansman S L, Quintana C, Bodian C, Griepp R B - Hypothermic circulatory arrest in operations on the thoracic aorta: determinants of operative mortality and neurologic autcome. $J$ Thorac Cardiovasc Surg 1994; 107: 788-99.

15 Rokkas C K \& Kouchoukos N T - Single-stage extensive replacement of the thoracic aorta: the arch-first technique. J Thorac Cardiovasc Surg 1999; 117: 99-105. 